\title{
Cytogenetic Evidence That Carcinoma In Situ is the Precursor Lesion for Invasive Testicular Germ Cell Tumors
}

\author{
Jannie van Echten, Ruud J. H. L. M. van Gurp, Marian Stoepker, \\ Leendert H. J. Looijenga, Bauke de Jong, and J. Wolter Oosterhuis
}

\begin{abstract}
A cytogenetic study of two cases of carcinoma in situ of the testis (CIS) and their adjacent invasive tumors, one a nonseminomatous germ cell tumor (NS) and one a seminoma (SE), revealed similarities in chromosomal pattern between the CIS and the invasive lesion in the same patient. These findings present for the first time cytogenetic evidence that CIS of the testis and its adjacent germ cell tumor are clonally related, which suggests that the CIS is indeed the precursor lesion of the invasive tumor.
\end{abstract}

\section{INTRODUCTION}

Testicular germ cell tumors (TGCTs) are thought to be derived from dysplastic germ cell precursors (gonocytes), which progress to carcinoma in situ (CIS) [1]. This assumption is supported by the frequent observation of CIS in the testicular parenchyma surrounding invasive cancer [2], as well as by the development of invasive TGCT in patients where CIS had been diagnosed previously [3, 4]. Thus CIS is considered the precursor for all subtypes of TGCTs of adolescents and adults, with the possible exception of spermatocytic seminoma [1].

CIS cells have a characteristic morphology ([5] for review) and their ploidy varies from peritriploid to pentaploid [6-10]. Cytogenetic data of CIS are limited to only three cases, reported by us [11]. Karyotyping of CIS is troublesome, because tissue culturing has not been successful thus far, and direct harvesting is difficult because of the small number of tumor cells that can be obtained from the seminiferous tubules. Cytogenetics of CIS is important to understand the progression of CIS to invasive tumor and to shed light on the pathogenesis of TGCTs.

In two cases, one seminoma (SE) and one nonseminomatous TGCT (NS), we succeeded in karyotyping both

From the Department of Medical Genetics $(J$. v. E., M. S., B. d. J.), University of Groningen, and Laboratory of Experimental Patho-Oncology (R. J. H. L. M. v. G., L. H. J. L., J. W. O.), Dr. Daniel den Hoed Cancer Center, Academic Hospital Rotterdam, The Netherlands.

Address reprint requests to: Jannie van Echten, Department of Medical Genetics, Ant. Deasinglaan 4, 9713 AW Groningen, The Netherlands.

Received February 13, 1995; accepted June 9, 1995 the invasive tumor and the CIS in the surrounding parenchyma.

\section{CASE REPORTS}

Case I

A 40-year-old patient presented with a mass in his right testis. Histologic examination of the orchiectomy specimen showed a NS with the following components: embryonal carcinoma, immature teratoma, mature teratoma, and yolk sac tumor. The parenchyma adjacent to the tumor contained CIS. Remarkably, in one of the seminiferous tubules a trophoblastic giant cell was found in continuity with the CIS.

\section{Case II}

A 30-year-old patient presented with a mass in his right testis. Histologic examination of the orchiectomy specimen showed a SE with scattered trophoblastic giant cells. The parenchyma was largely atrophic. Within the seminiferous tubules there was extensive CIS.

\section{MATERIALS AND METHODS}

In both cases, after frozen section diagnosis material from the tumor and the parenchyma was separately processed for karyotyping.

Short-term culturing and harvesting of the invasive NS and direct harvesting of the invasive SE were performed as described [12, 13]. To obtain CIS cells the method for direct harvesting of SE was also applied to the remaining parenchyma, surrounding the invasive tumor, which on light microscopy showed CIS. 

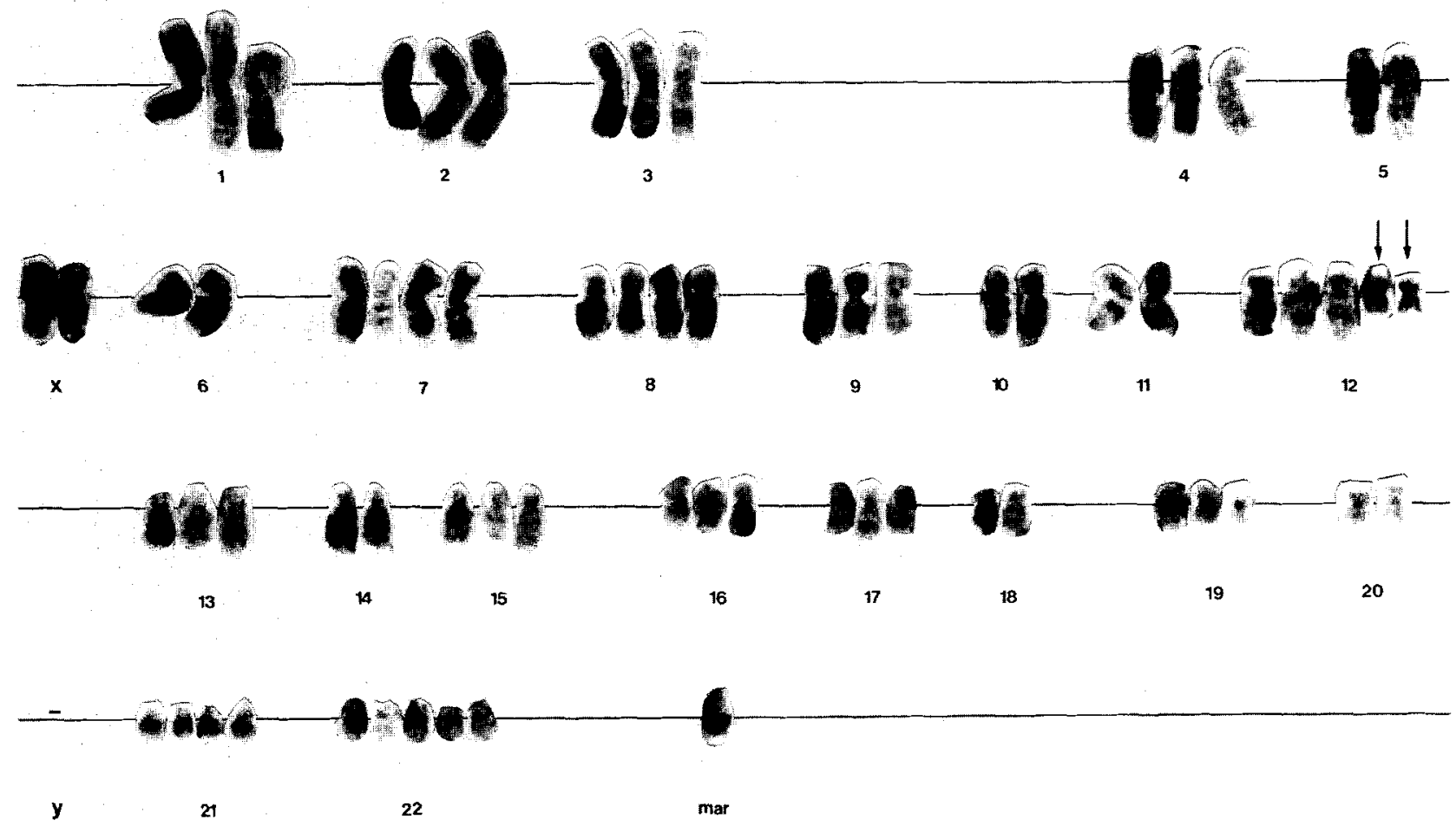

$\mathbf{a}$

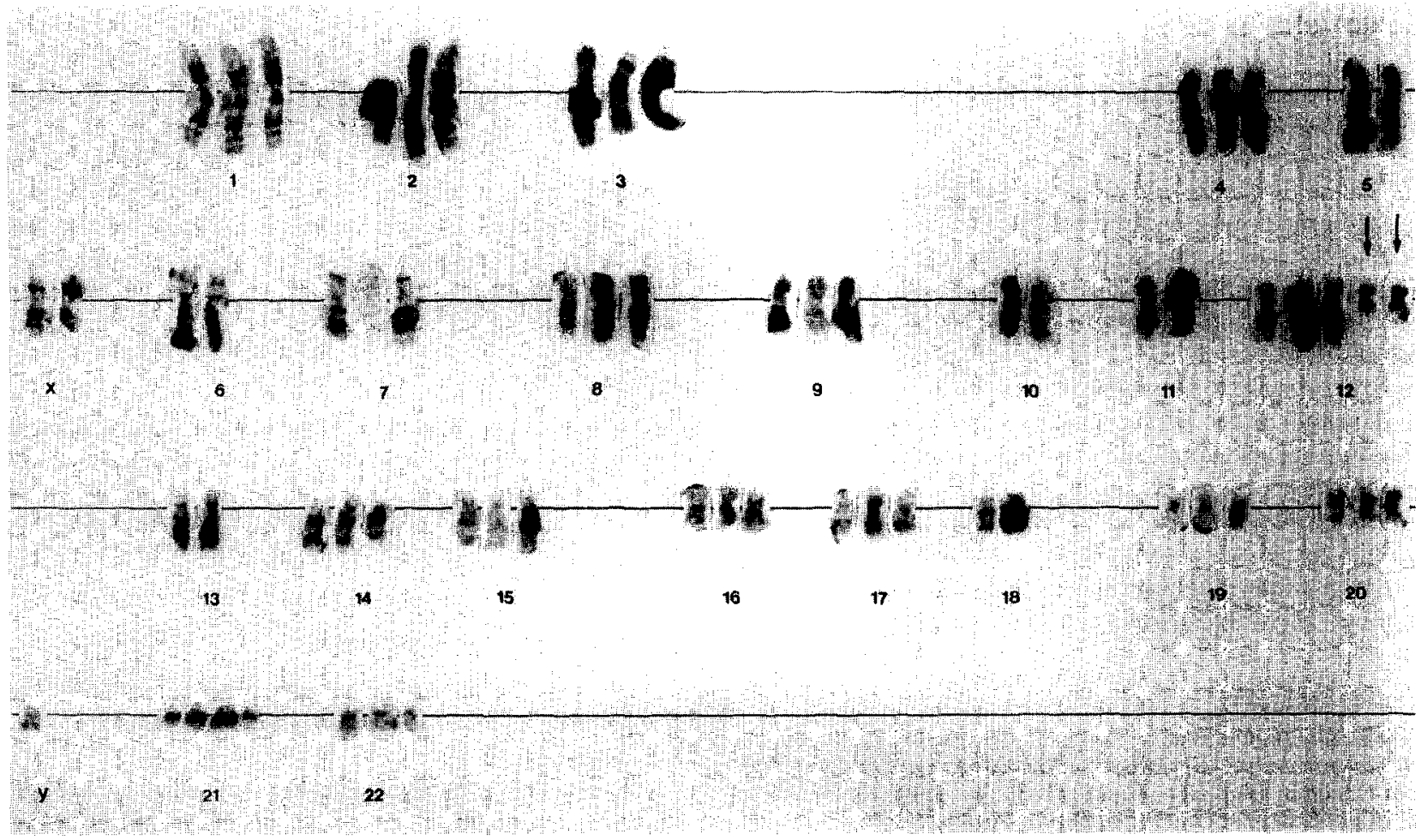

b

Figure 1 Representative karyotypes of the CIS (a) and invasive NS (b) of Case I with the following karyotype descriptions. a) CIS, $69, \mathrm{XX},-\mathrm{Y},-5,-6,+7,+8,-10,-11,+\mathrm{i}(12)(\mathrm{p} 10) \times 2,-14,-18,-20,+21,+22,+22,+\mathrm{mar}$; b) NS, 66, $\mathrm{XXY},-5,-6,-10, \sim 11,+\mathrm{i}(12)(\mathrm{p} 10) \times 2,-13,-18,+21$. 
CIS as a Precursor for Invasive TGCT
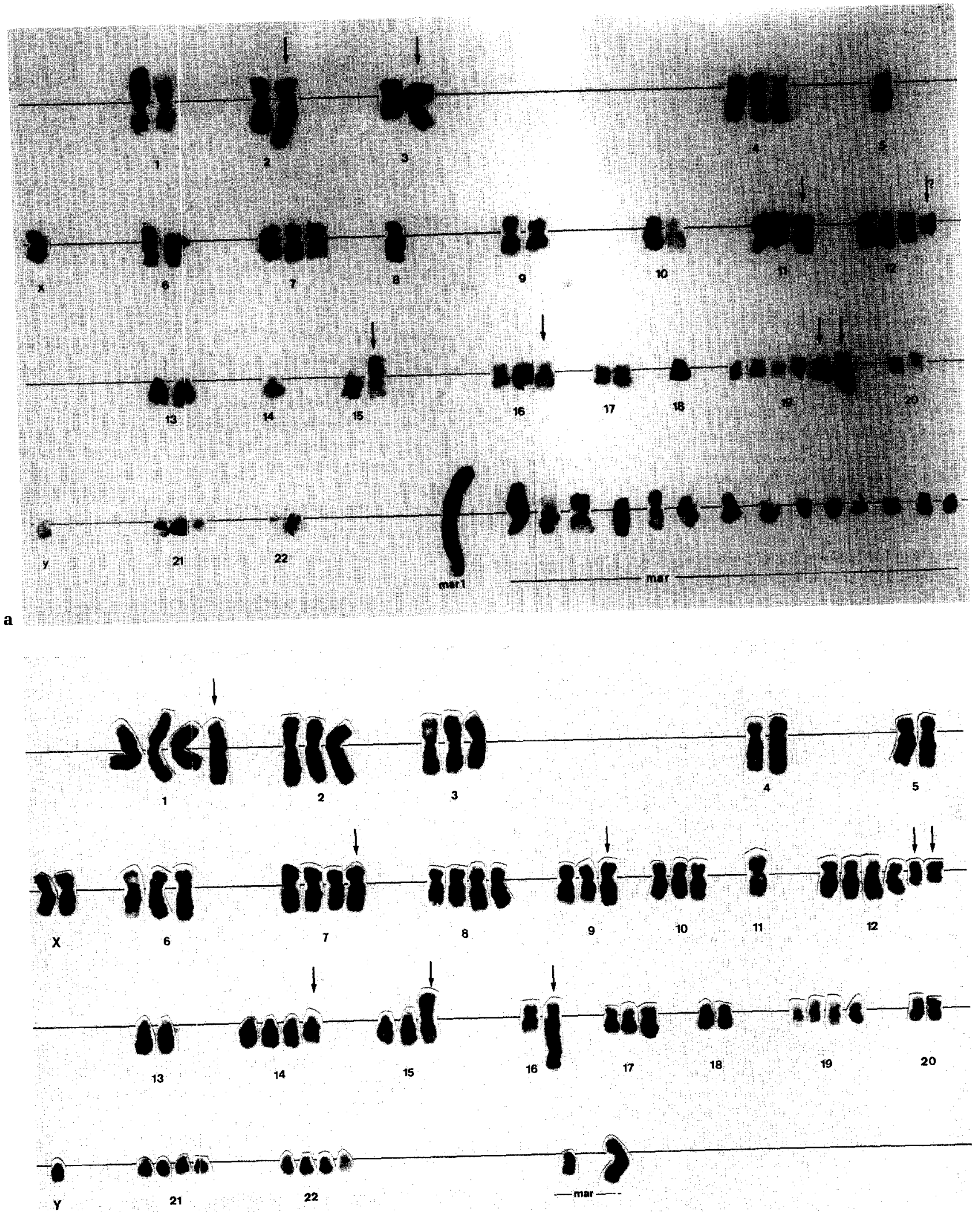

b

Figure 2 One of the two karyotypes of the CIS (a) and a representative karyotype of the invasive SE (b) of Case II with the following karyotype descriptions. a) CIS, $68, X Y,-X,-1,-2$, add(2)(q?), -3 , add(3)(q2?), $-5,-5,-6,-8,-8,-9,-10$, the

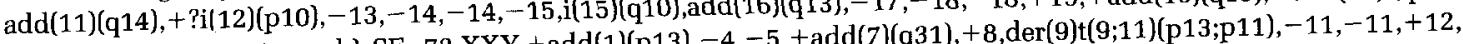

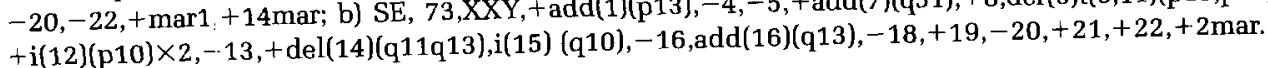


Table 1 Modal composite karyotypes of CIS and their invasive TGCTs

\begin{tabular}{|c|c|c|}
\hline \multirow[b]{2}{*}{ Case } & \multicolumn{2}{|c|}{ Modal composite karyotype } \\
\hline & Carcinoma in situ & Invasive tumor \\
\hline I & $\begin{array}{l}67-69, \mathrm{XXY},-5,-6,+8,-10,-11,+\mathrm{i}(12)(\mathrm{p} 10) \times 2 \\
\quad-18,-20,+21,+22[\mathrm{cp} 3]\end{array}$ & $\begin{array}{l}61-91, \mathrm{XXY},+\mathrm{Y},-5,-6,-10,-11,+\mathrm{i}(12)(\mathrm{p} 10) \times 2 \\
\quad-13,-18,+21,+22[\mathrm{cp} 10]\end{array}$ \\
\hline II & $\begin{array}{l}\text { Clonal structural abnormalities } \\
\text { add(2)(q?) } \\
\text { i(15)(q10) } \\
\text { add(19(q13) } \\
\text { mar1 }\end{array}$ & $\begin{array}{l}62-73, \mathrm{XXY},+\operatorname{add}(1)(\mathrm{p} 13),-3,-4,-5,+\operatorname{add}(7) \\
\text { (q31),der(9)t(9;11)(p13;p11),-11,-11,+12, } \\
\quad+\mathrm{i}(12)(\mathrm{p} 10) \times 2,-13, \mathrm{i}(15)(\mathrm{q} 10),-16, \operatorname{add}(16) \\
\text { (q13),-17,-18,+19,+21,+2-6mar[cp6] }\end{array}$ \\
\hline
\end{tabular}

Chromosomes were GPG banded (G-banding using Pancreatin [Sigma, P3292, 0.1\% in Hanks' solution] and Giemsa). A modal composite karyotype has been created according to ISCN 1991 [14]. However, the karyotypical descriptions are expressed in relation to the triploid level, to make specific over- and underrepresentation of chromosomes, an important feature of the chromosomal pattern of TGCTs, better visible and comparable [15].

\section{RESULTS}

From Case I three abnormal metaphases could be analyzed from the CIS component and 10 from the invasive tumor (NS). The representative karyotypes of the CIS and its invasive tumor, respectively are shown in Figures $1 \mathrm{a}$ and $1 \mathrm{~b}$.

From the CIS component of Case II two metaphases of substandard quality were found. From its invasive tumor (SE) six metaphases were analyzed. Figures $2 \mathrm{a}$ and $2 \mathrm{~b}$ show, respectively, one of the two karyotypes of the CIS and a representative karyotype of the invasive tumor.

Table 1 shows the modal composite karyotypes of CIS of Case I and the invasive tumors of both cases. Because of the substandard quality of the metaphases of the CIS of Case II no modal composite karyotype is presented. Only the clonal structural abnormalities in the two metaphases are noted.

Both cases of CIS revealed a peritriploid chromosome pattern: Case I $(n=68)$ and case II $(n \approx 65$; it was impossible to determine the exact chromosome number of the CIS component of Case II). The karyotypes of CIS and the invasive tumor of Case I show an identical modal number of copies of the chromosomes $X, 1,2,3,4,5,6,7,9,10,11$, $12,14,15,16,17,18,19,21$, and 22 . Moreover, they have an $\mathrm{i}(12 \mathrm{p})$ as common structural abnormality. In Case II an $\mathrm{i}(15 \mathrm{q})$ is present both in the CIS component and its invasive SE. An i(12p) chromosome, present in the invasive $\mathrm{SE}$, might be present in one of the metaphases of the CIS (Fig. 2a)

\section{DISCUSSION}

Carcinogenesis of TGCTs starts early in life, probably in utero $[1,16]$. Based on immunohistochemical and ultrastructural studies, CIS, derived from premalignant gonocytes [17-19], is supposed to be the precursor of all TGCTs of adolescents and adults except spermatocytic seminoma [1]. Cytogenetic investigations of CIS may support this view and are important to shed light on the pathogenesis of TGCTs and to understand the progression of CIS to invasive tumor.

In the two cases in which we succeeded in karyotyping both the invasive tumor and its adjacent CIS, we observed karyotypical similarities. In Case I, in CIS and its invasive NS, an identical number of modal copies of the chromosomes $X, 1,2,3,4,5,6,7,9,10,11,12,14,15,16,17,18$, 19,21 , and 22 , and $\mathrm{i}(12 \mathrm{p})$ was found. Despite the substandard quality of the two metaphases of CIS in Case II, we found an $\mathrm{i}(15 \mathrm{q})$ both in the CIS and SE. An i(12p) chromosome might also be present in both components. The karyotypical similarities between CIS and the invasive tumor in both cases demonstrate their clonal relationship and strongly suggest that we karyotyped the CIS that preceded the invasive cancer. As the testicular parenchyma adjacent to the tumor was free of invasive cancer, the abnormal metaphases harvested from the parenchyma must be derived from the CIS which was present in the seminiferous tubules. In our previous cytogenetic comparison of CIS with their invasive tumors (all NS) [11], no clear similarity was observed, except for two copies of $i(12 p)$ in both components in one case. It is conceivable that in these cases we failed to karyotype the CIS that was clonally related to the invasive tumor. CIS of the testis in general is very extensive [4] and sometimes heterogeneous [20].

In the present study the karyotypes of the two cases of CIS revealed a peritriploid chromosome pattern. This finding is in keeping with our previous cytogenetic studies [11], as well as with ploidy studies [6-9]. Polyploidization of a dysplastic germ cell precursor resulting in CIS is supposed to be an early event in the carcinogenesis of TGCTs ([21] for review). Noteworthy is the finding of an $\mathrm{i}(12 \mathrm{p})$ in the CIS component of the three $\mathrm{i}(12 \mathrm{p})$ positive invasive tumors (both cases in this study and Case 3 in our previous study [11]). This confirms that $\mathrm{i}(12 \mathrm{p})$ formation is an early event in the oncogenesis of TGCTs (for review [15, 22]), although most likely preceded by polyploidization [23].

In conclusion, our results present for the first time cytogenetic evidence that CIS is clonally related to and is the precursor for invasive TGCTs.

\section{REFERENCES}

1. Skakkebæk NE, Berthelsen JG, Giwercman A, Müller J (1987): Carcinoma-in-situ of the testis: possible origin from gono- 
cytes, and precursor of all types of germ cell tumors except spermatocytoma. Int J Androl 10:19-28.

2. Jacobsen GK, Hendriksen OB, von der Maase M (1981): Carcinoma in situ of testicular tissue adjacent to malignant germ cell tumors: a study of 10 cases. Cancer 47:2660-2662.

3. Giwercman A, Skakkebæk NE (1993): Carcinoma in situ of the testis: biology screening and management. Eur Urol 23 (suppl 2):19-21.

4. Giwercman A, van der Maase H, Skakkebæk NE (1993): Epidemiological and clinical aspects of carcinoma in situ of the testis. Eur Urol 23:104-114.

5. Soosay GN, Bobrow L, Happerfield L, Parkinson MC (1991): Morphology and immunohistochemistry of carcinoma in situ adjacent to testicular germ cell tumors in adults and children: implications for histogenesis. Histopathology 19:537544.

6. de Graaff WE, Oosterhuis JW, de Jong B, Dam A, van Putten WLJ, Castedo SMMJ, Sleijfer DTh, Schraffordt Koops H (1992): Ploidy of testicular carcinoma in situ. Lab Invest 66:166-168.

7. El-Naggar AK, Ro JY, McLemore D, Ayala AG, Batsakis JG (1992): DNA ploidy in testicular germ cell neoplasms. Histogenetic and clinical implications. Am J Surg Pathol 16:611618.

8. Nagler HM, Kaufman DG, O’Toole KM, Sawczuk IS (1990): Carcinoma in situ of the testis: diagnosis by aspiration flow cytometry. J Urol 143:359-361.

9. Nistal M, Codesal J, Paniagua R (1989): Carcinoma in situ of the testis in infertile men. A histological, immunocytochemical, and cytomorphometric study of DNA content. J Pathol 159:205-210.

10. Müller J, Skakkebæk NE (1981): Microspectrophotometric DNA measurements of carcinoma-in-situ germ cells in the testis. Int J Androl suppl 4:211-221.

11. Vos AM, Oosterhuis JW, de Jong B, Buist J, Schraffordt Koops $H$ (1990): Cytogenetics of carcinoma in situ of the testis. Cancer Genet Cytogenet 46:7.j-81.

12. Castedo SMMJ, de Jong E, Oosterhuis JW, Seruca R, Idenburg VJS, Dam A, te Meerman GJ, Schraffordt Koops H, Sleijfer DTh (1989): Chromosomal changes in human primary testic- ular nonseminomatous germ cell tumors. Cancer Res 49: 5696-5701.

13. Castedo SMMJ, de Jong B, Oosterhuis JW, Seruca R, te Meerman GJ, Dam A, Schraffordt Koops H (1989): Cytogenetic analysis of ten human seminomas. Cancer Res 49:439-443.

14. ISCN (1991): Guidelines for Cancer Cytogenetics, Supplement to an International System for Human Cytogenetic Nomenclature. Mitelman F (ed.) S. Karger, Basel.

15. de Jong B, Oosterhuis JW, Castedo SMMJ, Vos AM, te Meerman GJ (1990): Pathogenesis of adult testicular germ cell tumors. A cytogenetic model. Cancer Genet Cytogenet 48: 143-167.

16. Forman D, Møller H (1994): Testicular cancer. Cancer Surv 19/20:323-341.

17. Gondos B (1993): Ultrastructure of developing and malignant germ cells. Eur Urol 23:68-75.

18. Giwercman A, Andrews PW, Jørgensen N, Müller J, Græm N, Skakkebæk NE (1993): Immunohistochemical expression of embryonal marker TRA-1-60 in carcinoma in situ and germ cell tumors of the testis. Cancer 72:1308-1314.

19. Giwercman A, Müller J, Skakkebæk NE (1991): Carcinoma in situ of the testis: possible origin, clinical significance, and diagnostic methods. Recent Results in Cancer Res 123:21-36.

20. Gillis AJM, Looijenga LHJ, de Jong B, Oosterhuis JW (1994): Clonality of combined testicular germ cell tumors of adults. Lab Invest 71:874-878.

21. Oosterhuis JW, Castedo SMMJ, de Jong B, Cornelisse CJ, Dam A, Sleijfer DTh, Schraffordt Koops H (1989): Ploidy of primary germ cell tumors of the testis. Pathogenetic and clinical relevance. Lab Invest 60:14-20.

22. Bosl GJ, Dmitrovsky E, Reuter VE, Samaniego F, Rodriguez E, Geller NL, Chaganti RSK (1989): Isochromosome of chromosome 12: clinically useful marker for male germ cell tumors. J Natl Cancer Inst 81:1874-1878.

23. Geurts van Kessel A, van Drunen E, de Jong B, Oosterhuis JW Langeveld A, Mulder MP (1989): Chromosome 12q heterozygosity is retained in $\mathrm{i}(12 \mathrm{p})$-positive testicular germ cell tumor cells. Cancer Genet Cytogenet 40:129-134. 